\title{
BMJ Open Effect of vitreomacular adhesion and vitreous gel on age-related reduction of macular thickness: a retrospective observational study
}

\author{
Kazuyuki Kumagai, ${ }^{1}$ Masanori Hangai, ${ }^{2}$ Mariko Furukawa, ${ }^{1}$ Tetsuyuki Suetsugu, ${ }^{1}$ \\ Nobuchika Ogino ${ }^{3}$
}

To cite: Kumagai $\mathrm{K}$ Hangai M, Furukawa $\mathrm{M}$, et al. Effect of vitreomacular adhesion and vitreous gel on age-related reduction of macular thickness: a retrospective observational study. BMJ Open 2016;6: e012972. doi:10.1136/ bmjopen-2016-012972

- Prepublication history and additional material is available. To view please visit the journal (http://dx.doi.org/ 10.1136/bmjopen-2016012972).

Received 9 June 2016 Revised 12 August 2016 Accepted 6 September 2016

CrossMark

\section{${ }^{1}$ Kami-iida Daiichi General Hospital, Aichi, Japan \\ ${ }^{2}$ Department of \\ Ophthalmology, Faculty of Medicine, Saitama Medical University, Iruma, Japan ${ }^{3}$ Shinjo Ophthalmologic Institute, Miyazaki, Japan}

Correspondence to Dr Kazuyuki Kumagai; ganka@kamiiida-hp.jp

\section{ABSTRACT}

Objective: To investigate the effects of vitreomacular adhesion (VMA), vitreomacular separation (VMS) and absence of vitreous gel due to vitrectomy on macular thickness measured in the spectral domain optical coherence tomographic (SD-OCT) images.

Design: A longitudinal, retrospective, observational study.

Setting: Secondary multicentre study.

Participants: 218 eyes of 218 healthy patients and 119 vitrectomised eyes of 119 patients were studied. The healthy individuals were classified into a VMA group (54 eyes) and a VMS group (164 eyes), while the vitrectomised patients were classified into an internal limiting membrane (ILM)-on group (26 eyes) and an ILM-off group (93 eyes). In all participants, 2 Cirrus HD-OCT recordings were made with an average interval of 36 months (range 24-60 months).

Primary and secondary outcome measures: The primary outcome measure was the rate of change in macular thickness in the central sector. The secondary outcomes were the rates of change in macular thickness in the inner 4 sectors.

Results: The annual rate of change in the macular thickness of the central sector was $0.76 \pm 1.8 \mu \mathrm{m} / \mathrm{year}$ in the VMA group, $-0.58 \pm 2.3 \mu \mathrm{m} /$ year in the VMS group, $-1.57 \pm 1.9 \mu \mathrm{m} / \mathrm{year}$ in the ILM-on group and $-0.86 \pm 3.1 \mu \mathrm{m} /$ year in the ILM-off group. There was a significant difference between the rate of the central sector thickness change in the VMA and VMS groups ( $p=0.0001)$. The presence of VMA was a significant factor associated with an increase in the central sector thickness $(p=0.0055)$. When the healthy and ILM-on groups were compared, the rate of decrease in the central sector thickness was faster in the ILM-on group $(p=0.0043)$. Multiple regression analyses showed that not peeling the ILM during the vitrectomy was a significant factor associated with a decrease in the central sector thickness $(p=0.044)$.

Conclusions: The presence of a VMA and a vitreous gel may help restrain the macular thickness reduction.
Strengths and limitations of this study

- The patients in vitrectomised groups were examined at least 1 year after the vitrectomy when the confounding effects of surgery were somewhat mitigated.

- The vitrectomised group had concomitant diseases that were treated during the surgery and this may have influenced the changes in the macular thickness independent of the vitreous separation.

- The sample size was different in each group with the internal limiting membrane-on group being the fewest with 26 eyes.

\section{INTRODUCTION}

Histological studies have demonstrated that the thickness of the retinal ganglion cell and nerve fibre layers decreases with increasing age. $^{12}$ The results of several optical coherence tomographic (OCT) studies have shown that ageing has different effects on the retinal thickness. ${ }^{3-14}$ The disparities among these reports may be due to the differences in the characteristics of the participants, the types of OCT devices used, the retinal thickness parameters measured and the study design.

The resolution of the spectral domain OCT (SD-OCT) instruments have improved with faster scanning speeds compared to time-domain OCT instruments. ${ }^{15}$ The most valid approach to examine the age-related reductions in the macular thickness is to examine the serial changes in the same eyes over time, that is, a longitudinal study instead of a cross-sectional study.

We hypothesise that the presence of vitreous gel prevents a decrease in macular thickness. Thus, the purpose of this study was to determine the rates of change in the average 
macular thicknesses in four groups of eyes: eyes with a vitreomacular adhesion (VMA), eyes with a vitreomacular separation (VMS), eyes after vitrectomy with internal limiting membrane (ILM) peeling (ILM-off), and eyes after the vitrectomy without ILM peeling (ILM-on). To accomplish this, SD-OCT images were obtained by the Cirrus HD-OCT with the macular change analysis programme. The images were collected from each eye at two time points with an average interval of 36 months. The rate of change in the different macular sector thickness was determined for these four groups.

\section{MATERIALS AND METHODS}

\section{Participants}

This was a longitudinal, retrospective study of individuals who were examined at the Shinjo Ophthalmologic Institute, Kami-iida Daiichi General Hospital and the Nishigaki Eye Clinic from October 2007 through December 2015. The individuals consisted of healthy controls and the patients who had undergone vitrectomy. The healthy controls (healthy group) were the patients who were being followed because of a cataract and did not have any retinal diseases. The healthy group was classified into a VMA group consisting of 54 eyes and a VMS group consisting of 164 eyes. The VMA status was confirmed to be the same in each of the SD-OCT images in all participants of the healthy group.

The patients without vitreous gel (vitrectomised group) had undergone vitrectomy with or without ILM peeling for several types of retinal diseases. The first measurement was made at least 1 year after the vitrectomy. The vitrectomy was performed on 110 eyes with a macular hole $(\mathrm{MH}), 5$ eyes with a rhegmatogenous retinal detachment without involvement of the macula and 4 eyes with vitreous haemorrhage.

Signed informed consent was obtained from all the participants for the procedures used during the examinations.

\section{Examinations}

Each of the participants had a comprehensive ophthalmological examination including measurements of the refractive error, best-corrected visual acuity (BCVA) with a Landolt chart at $5 \mathrm{~m}$, axial length by ocular biometry (IOL Master; Carl Zeiss Meditec) and intraocular pressure with a Goldmann applanation tonometer. In addition, the eyes were examined by slit-lamp biomicroscopy, dilated indirect slit-lamp biomicroscopy with and without contact lenses, indirect ophthalmoscopy and SD-OCT.

\section{Inclusion and exclusion criteria}

The inclusion criteria for both groups were OCT image signal intensity $\geq 7$, axial length $<28.00 \mathrm{~mm}$ and age $\geq 56$ years at the time of the first OCT measurements. The inclusion criteria for the healthy group were BCVA $\geq 20 / 20$, no significant cataract and normal foveal contour. The inclusion criteria for the vitrectomised group were outpatient visit continued $>3$ years after the vitrectomy with OCT images available at each visit and the VMA status remain unchanged at these visits.

The exclusion criteria for both groups were persistent centring and segmentation errors. In addition, the individuals with any ocular or systemic disorders that could affect the retinal thickness, for example, glaucoma, optic nerve diseases and diabetes mellitus, were excluded. The exclusion criteria only for the healthy group were unclear VMA status, that is, cases in which full adhesion or detachment of the posterior vitreous could not be determined, vitreomacular traction, foveal deformation and the change in VMA status at the second OCT scan. The exclusion criteria only for the vitrectomised group were outpatient visit continued $<3$ years after the vitrectomy.

\section{Surgical treatments}

All surgeries were performed by one surgeon $(\mathrm{NO})$. All phakic patients underwent pars plana vitrectomy with phacoemulsification and implantation of a posterior chamber intraocular lens. The posterior hyaloid membrane and vitreous gel were removed, and the ILM was made visible with triamcinolone acetonide and peeled for three disc diameters around the fovea. ILM peeling was performed on 93 eyes, and the ILM was not peeled in 26 eyes. In the $\mathrm{MH}$ eyes, sulfur hexafluoride gas was used for tamponade, and the patients were instructed to maintain a prone position for 7 days.

\section{HD-OCT recordings}

The Cirrus HD-OCT (Carl Zeiss Meditec, Dublin, California, USA) was used to obtain axial images of the vitreoretinal interface. At least five B-scan images of $6 \mathrm{~mm}$ in length passing through the fovea along the horizontal and vertical axes were recorded with a 4096 A-scan resolution and $0.25 \mathrm{~mm}$ intervals between neighbouring B-scans. The average regional thicknesses of the Early Treatment Diabetic Retinopathy Study (ETDRS) sectors and $6 \times 6 \mathrm{~mm}$ macular cube scans were composed of 200 B-scans and 200 A-scans centred on the fovea. Experienced OCT examiners scanned the retina at least three times to obtain images with a signal intensity of $\geq 7$. The images with centring or segmentation errors were excluded. The retinal thickness was automatically measured with the vitreoretinal interface as the inner border of the retina and the anterior border of the retinal pigment epithelium as the outer border of the retina.

The average increase or decrease in the retinal thickness/year was determined using the Cirrus macular change analysis programme. The macular change analysis programme compares the OCT scans from consecutive examinations. The retinal alignment, which was based on the vessel landmarks to the initial OCT images, was done automatically. The analyses were made 
on the central and inner four ETDRS sectors with a mean interval of 36 months (range, 24-60 months) between two observational scans. For the vitrectomised group, a first OCT scan was recorded at least 1 year after the vitrectomy. Then a second OCT scan was recorded at least 2 years after the first scan. Therefore, all patients from this group were examined for at least 3 years after the vitrectomy. When several OCT scans were available from the same patient, only the latest scan was selected for the analysis.

\section{Statistical analyses}

Unpaired t-tests were used to determine the significance of the differences in the numerical data, and $\chi^{2}$ tests were used for the categorical data between each group. Multivariate regression analyses were used to determine the associations between the rate of macular thickness change and the clinical factors, for example, sex, age, axial length, presence of VMA and ILM peeling. A p $<0.05$ was accepted as statistically significant. Statview software V.5.0 (SAS Institute, Cary, North Carolina, USA) was used for the statistical analyses.

\section{RESULTS}

The baseline characteristics of the people and the mean rates of macular thickness change in the VMA, VMS, ILM-on and ILM-off groups are shown in table 1. The
MHs were closed in all 110 eyes after the vitrectomy, and no surgical complications were observed in the vitrectomised group. For the healthy group, the central and inner four sectors were significantly thinner in the VMS group than in the VMA group. For the vitrectomised group, the rate of macular thickness decrease in the central sector was faster in the ILM-on group than in the ILM-off group. In contrast, the rate of macular thickness decrease in the inner four sectors was slower in the ILM-on group than in the ILM-off group, but the decrease was only significant in the inner inferior sector $(p=0.032)$. The persons in the VMS group were significantly older than those in the VMA group $(p<0.0001)$.

The results of the multiple regression analyses for macular thickness changes among the healthy groups are shown in table 2. The presence of VMA was a significant factor associated with the increase in macular thicknesses in all sectors $(\mathrm{p}<0.0002-0.0055)$.

The results of the multiple regression analysis for macular thickness changes in the vitrectomised group are shown in table 3. The ILM peeling was a factor significantly associated with a decrease in macular thicknesses in the inner temporal and inferior sectors $(\mathrm{p}=0.0096$ and $\mathrm{p}=0.0047$, respectively). The central sector thickness was not affected by the ILM peeling ( $\mathrm{p}=0.58)$.

The baseline characteristics and macular thickness changes in the healthy and ILM-on groups are shown in table 4. The rate of macular thickness decrease was

Table 1 Baseline characteristics and macular thickness changes

\begin{tabular}{|c|c|c|c|c|c|c|}
\hline & \multicolumn{2}{|c|}{ Healthy group } & \multirow[b]{2}{*}{ p Value } & \multicolumn{2}{|c|}{ Vitrectomised group } & \multirow[b]{2}{*}{ p Value } \\
\hline & VMA $(n=54)$ & VMS $(n=164)$ & & ILM-on $(n=26)$ & ILM-off $(n=93)$ & \\
\hline Women number (\%) & $31(57.4)$ & $118(72.0)$ & $0.046^{*}$ & $14(53.8)$ & $66(71.0)$ & $0.10^{*}$ \\
\hline Age (years) & $65.2 \pm 6.4$ & $69.3 \pm 6.5$ & $<0.0001 \dagger$ & $69.9 \pm 7.3$ & $68.4 \pm 6.0$ & $0.27 \dagger$ \\
\hline Range & $(56-84)$ & $(56-86)$ & & $(56-80)$ & $(57-80)$ & \\
\hline Axial length (mm) & $23.5 \pm 1.2$ & $23.6 \pm 1.2$ & $0.95 \dagger$ & $24.1 \pm 1.6$ & $23.3 \pm 1.3$ & $0.012 \dagger$ \\
\hline Range & $(21.0-26.1)$ & $(21.3-27.1)$ & & (22.1-27.0) & $(21.5-27.7)$ & \\
\hline \multicolumn{7}{|l|}{ Sectors ( $\mu \mathrm{m} /$ year) } \\
\hline Central & $0.76 \pm 1.8$ & $-0.58 \pm 2.3$ & $0.0001 \dagger$ & $-1.57 \pm 1.9$ & $-0.86 \pm 3.1$ & $0.27 \dagger$ \\
\hline Inner superior & $0.23 \pm 1.8$ & $-0.97 \pm 2.1$ & $0.0002 \dagger$ & $-1.95 \pm 2.0$ & $-2.14 \pm 2.3$ & $0.69 \dagger$ \\
\hline Inner temporal & $0.096 \pm 1.6$ & $-0.92 \pm 2.1$ & $0.0016 \dagger$ & $-1.51 \pm 1.8$ & $-2.47 \pm 2.3$ & $0.054 \dagger$ \\
\hline Inner inferior & $0.20 \pm 1.5$ & $-1.13 \pm 2.1$ & $<0.0001 \dagger$ & $-1.29 \pm 1.8$ & $-2.40 \pm 2.4$ & $0.032 \dagger$ \\
\hline Inner nasal & $0.072 \pm 1.6$ & $-0.94 \pm 2.0$ & $0.0011 \dagger$ & $-1.51 \pm 1.9$ & $-1.72 \pm 2.5$ & $0.68 \dagger$ \\
\hline
\end{tabular}

Table 2 Multiple regression analysis for macular thickness changes among the healthy group

\begin{tabular}{|c|c|c|c|c|c|c|c|c|c|c|}
\hline & \multicolumn{2}{|l|}{ Central } & \multicolumn{2}{|c|}{ Superior } & \multicolumn{2}{|c|}{ Temporal } & \multicolumn{2}{|l|}{ Inferior } & \multicolumn{2}{|l|}{ Nasal } \\
\hline & $\bar{\beta}$ & p Value & $\bar{\beta}$ & p Value & $\boldsymbol{\beta}$ & p Value & $\boldsymbol{\beta}$ & p Value & $\boldsymbol{\beta}$ & p Value \\
\hline Women & -0.041 & 0.58 & -0.022 & 0.76 & -0.066 & 0.38 & -0.056 & 0.45 & -0.016 & 0.83 \\
\hline Age & -0.11 & 0.13 & -0.085 & 0.23 & -0.032 & 0.66 & -0.060 & 0.40 & -0.030 & 0.68 \\
\hline Axial length & -0.13 & 0.087 & -0.12 & 0.12 & -0.088 & 0.25 & -0.073 & 0.33 & -0.077 & 0.31 \\
\hline Presence of VMA & 0.20 & 0.0055 & 0.24 & 0.001 & 0.20 & 0.0048 & 0.27 & 0.0002 & 0.22 & 0.0021 \\
\hline
\end{tabular}


Table 3 Multiple regression analysis for macular thickness changes among the vitrectomised group

\begin{tabular}{|c|c|c|c|c|c|c|c|c|c|c|}
\hline & \multicolumn{2}{|l|}{ Central } & \multicolumn{2}{|c|}{ Superior } & \multicolumn{2}{|c|}{ Temporal } & \multicolumn{2}{|c|}{ Inferior } & \multicolumn{2}{|l|}{ Nasal } \\
\hline & $\bar{\beta}$ & p Value & $\bar{\beta}$ & p Value & $\overline{\boldsymbol{\beta}}$ & p Value & $\bar{\beta}$ & p Value & $\overline{\boldsymbol{\beta}}$ & p Value \\
\hline Women & -0.005 & 0.96 & 0.15 & 0.15 & 0.024 & 0.81 & 0.10 & 0.32 & 0.10 & 0.32 \\
\hline Age & -0.19 & 0.053 & -0.19 & 0.048 & -0.17 & 0.083 & -0.20 & 0.038 & -0.079 & 0.42 \\
\hline Axial length & -0.058 & 0.60 & -0.18 & 0.11 & -0.21 & 0.059 & -0.13 & 0.21 & -0.22 & 0.049 \\
\hline ILM peeling & 0.054 & 0.58 & -0.13 & 0.17 & -0.25 & 0.0096 & -0.27 & 0.0047 & -0.11 & 0.25 \\
\hline
\end{tabular}

Table 4 Baseline characteristics and macular thickness changes in the healthy and ILM-on groups

\begin{tabular}{llll}
\hline & $\begin{array}{l}\text { Healthy } \\
(\mathbf{n = 2 1 8 )}\end{array}$ & $\begin{array}{l}\text { ILM-on } \\
(\mathbf{n = 2 6 )}\end{array}$ & $\mathbf{p}$ Value \\
\hline Women number (\%) & $149(68.3)$ & $14(53.8)$ & $0.14^{*}$ \\
Age (years) & $65.3 \pm 6.7$ & $69.9 \pm 7.3$ & $0.24 \dagger$ \\
Range & $(56-86)$ & $(56-80)$ & \\
Axial length (mm) & $23.6 \pm 1.2$ & $24.1 \pm 1.6$ & $0.035 \dagger$ \\
Range & $(21.0-27.1)$ & $(22.1-27.0)$ & \\
Sectors ( $\mu$ m/year) & & & \\
$\quad$ Central & $-0.25 \pm 2.2$ & $-1.57 \pm 1.9$ & $0.0043 \dagger$ \\
$\quad$ Inner superior & $-0.68 \pm 2.1$ & $-1.95 \pm 2.0$ & $0.0038 \dagger$ \\
$\quad$ Inner temporal & $-0.67 \pm 2.1$ & $-1.51 \pm 1.8$ & $0.046 \dagger$ \\
$\quad$ Inner inferior & $-0.80 \pm 2.1$ & $-1.29 \pm 1.8$ & $0.24 \dagger$ \\
$\quad$ Inner nasal & $-0.69 \pm 2.0$ & $-1.51 \pm 1.9$ & $0.049 \dagger$ \\
\hline${ }^{*} \chi^{2}$ test. & & & \\
†Unpaired t-test. & & & \\
ILM, internal limiting membrane. & &
\end{tabular}

significantly faster in the ILM-on group than in the healthy group (VMA+VMS groups).

The results of the multiple regression analysis for macular thickness changes in the healthy and ILM-on groups are shown in table 5 . The rate of decrease in the macular thickness was significantly faster in the central and inner superior sectors of the ILM-on group ( $p=0.044$ and $p=0.028$, respectively).

The rates of macular thickness changes in the central sectors are shown in figure 1 . The thickness of the central macular sector increased in the VMA group, while it decreased in the VMS, ILM-on and ILM-off groups. The decrease in the central sector thickness was fastest in the ILM-on group.

Also, we have provided online supplementary tables S1-5 showing the data from tables $1-5$ in percentage of the macular thickness changes.

\section{DISCUSSION}

We determined the rates of macular thickness change in the central and inner four ETDRS sectors obtained by the Cirrus macular change analysis programme from longitudinal measurements of the healthy and vitrectomised individuals. The macular change analysis programme compared the thickness of identical macular regions so that even slight changes in the macular thickness over time could be detected.
The macular thickness increased in all sectors in the VMA group with the rates ranging from 0.072 to $0.76 \mu \mathrm{m} /$ year. Batta et $a l^{16}$ suggested that the retinal nerve fibre layer (RNFL) is thicker in patients with a partial posterior vitreous detachment (PVD) than in controls without a partial PVD. Vitreous traction on the macular area may be the reason for the increase in macular thickness. ${ }^{16}$ In contrast, the macular thickness decreased in all sectors of the VMS group with the rates ranging from -0.58 to $-1.13 \mu \mathrm{m}$ /year. Multiple regression analyses showed that the presence of VMA was a significant factor that restricted the reduction of the macular thickness in all sectors. This suggests that the presence of the vitreous gel and VMA may be factors restraining the age-related reduction of the macular thickness.

In the VMS group, the mean rate of change in the central sector was slower at $-0.58 \mu \mathrm{m} /$ year than in the inner four sectors at -0.92 to $-1.13 \mu \mathrm{m} /$ year. The extrafoveal thickness decreased more with ageing than did the central foveal thickness. The reason for this is the anatomical effects of ageing on the macular region. The inner retinal layer is thinnest in the central fovea while the outer retinal layer is thickest in this area. ${ }^{13}$ The inner retinal thickness over the whole macular area decreased with ageing while the outer retinal thickness did not decrease with ageing. ${ }^{13}$ Therefore, some authors have reported that the extrafoveal thickness which is affected by the inner retinal thickness decreased with ageing, ${ }^{5} 68$ 10-12 while the central foveal thicknesses did not change with ageing. ${ }^{4-9} 14$

Other authors have reported that the central foveal thickness increases with increasing age. ${ }^{510} 11$ The significant differences in the mean ages of the VMA and VMS groups may have affected our results. However, the multiple regression analyses of the healthy group showed that age was not significantly associated with the macular thickness. Instead, the presence of VMA was a significant factor associated with the macular thickness increase in each sector. The results of the earlier studies showed that the central foveal thickness increased with increasing age both in the VMA and VMS groups. Thus, the proportion of individuals with VMA may be higher in these reports leading to the observed increase in the central sector thickness.

In the vitrectomised group, the macular thickness decreased in all of the sectors. The rate of macular 
Table 5 Multiple regression analysis for macular thickness changes in the healthy and ILM-on groups

\begin{tabular}{|c|c|c|c|c|c|c|c|c|c|c|}
\hline & \multicolumn{2}{|l|}{ Central } & \multicolumn{2}{|c|}{ Superior } & \multicolumn{2}{|c|}{ Temporal } & \multicolumn{2}{|l|}{ Inferior } & \multicolumn{2}{|l|}{ Nasal } \\
\hline & $\bar{\beta}$ & p Value & $\bar{\beta}$ & p Value & $\bar{\beta}$ & p Value & $\boldsymbol{\beta}$ & p Value & $\bar{\beta}$ & p Value \\
\hline Women & -0.058 & 0.42 & -0.019 & 0.79 & -0.079 & 0.28 & -0.081 & 0.27 & -0.025 & 0.73 \\
\hline Age & -0.16 & 0.017 & -0.13 & 0.058 & -0.064 & 0.35 & -0.12 & 0.087 & -0.066 & 0.33 \\
\hline Axial length & -0.13 & 0.083 & -0.16 & 0.028 & -0.10 & 0.18 & -0.086 & 0.25 & -0.12 & 0.11 \\
\hline ILM-on & -0.14 & 0.044 & -0.15 & 0.028 & -0.11 & 0.092 & -0.056 & 0.41 & -0.11 & 0.10 \\
\hline
\end{tabular}

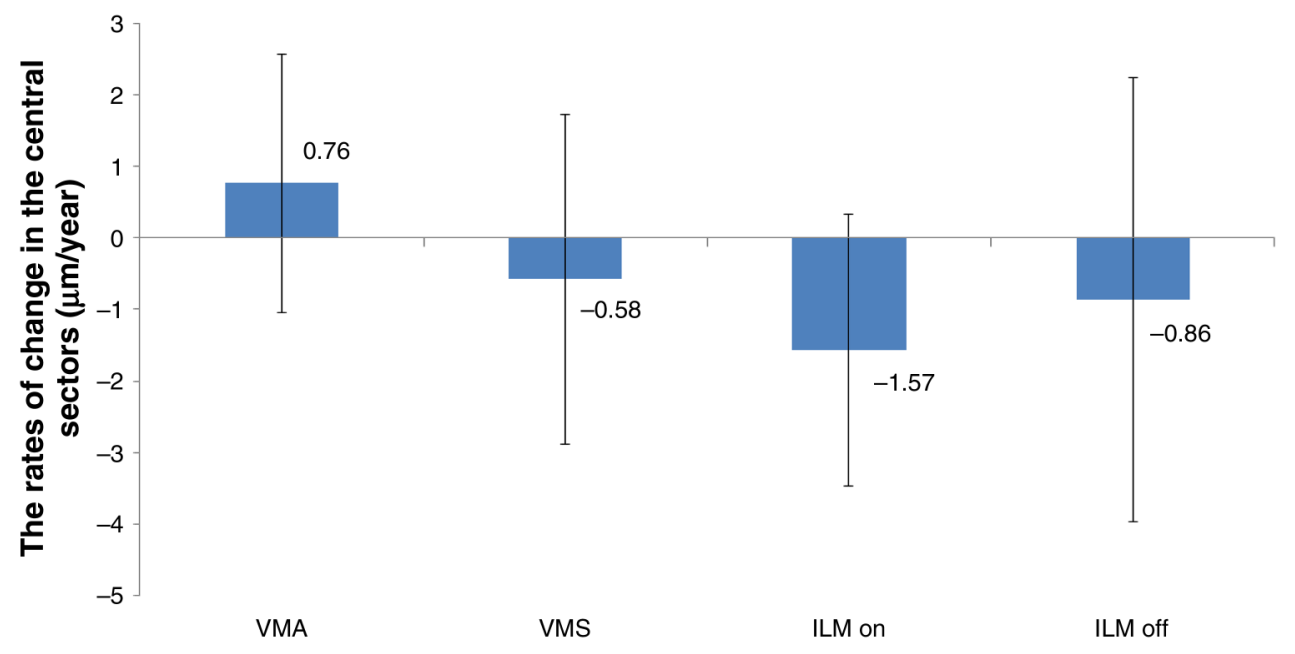

Status of the eyes

Figure 1 The rates of macular thickness changes in the central sectors of each group. The central sector macular thickness increases in the VMA group, while it decreases in the VMS, ILM-on and ILM-off groups. The decrease in the central sector thickness was fastest in the ILM-on group. The error bars represent the SDs. ILM, internal limiting membrane; VMA, vitreomacular adhesion; VMS, vitreomacular separation.

thickness decrease was faster in the central sector of the ILM-on group at $-1.57 \mu \mathrm{m} /$ year. In contrast, the rate of decrease was faster in the inner four sectors of the ILM-off group at -1.72 to $-2.47 \mu \mathrm{m}$ /year. ILM peeling tended to increase the rate of macular thickness reduction in the inner temporal and inferior sectors (table 3). However, the ILM-on group consisted of only 26 eyes (21.8\% of all vitrectomised eyes), so the results may show significant differences in other sectors if more data were available in this group.

The eyes with and without vitreous gel (the healthy group and the ILM-on group, respectively) were compared to analyse if the presence of the vitreous gel prevented the decrease in macular thickness. The ILM-off group was excluded from this comparison because the macular thicknesses were shown to be significantly affected by ILM peeling in table 3. When the healthy and ILM-on groups were compared, all sectors except the inner inferior sectors decreased at significantly faster rates in the ILM-on group. In contrast, multiple regression analyses showed that leaving ILM-on during the vitrectomy was significantly associated with the decrease in the central and inner superior sector thicknesses. Although there are differences in the rate of decrease in each sector, the removal of vitreous gel seems to facilitate the macular thickness decrease. Other factors contributing to the macular thickness decrease may be surgical damage, natural course of the disease, secondary glaucoma and the absence of the vitreous gel traction after the vitrectomy, although it was difficult to measure the effects of these factors unambiguously.

Although our study showed that the annual change in macular thicknesses for each group was significant, the amount of change was very small (mostly $<1 \mu \mathrm{m})$. Our hypothesis was based on the idea that the retinal oxygen distribution change occurring after the vitreous gel removal will eventually lead to retinal thinning. Vitrectomy leads to an increase in the retinal oxygen concentration. ${ }^{17}$ Elevated intraocular oxygen levels tend to be beneficial for the resolution of macular oedema, but may contribute to the development of nuclear cataract and primary open-angle glaucoma. ${ }^{18-20}$ An intact vitreous gel may play an active role in preventing retinal tissue damage from free oxygen radicals. ${ }^{19} 20$ Since the vitreous gel undergoes liquefaction by ageing or surgical 
removal, the fluid that replaces the vitreous gel promotes a rapid distribution of oxygen within the eye through fluid mixing, ${ }^{18-20}$ leading to a wider area of retinal tissue damages and thinning by exposure to free radicals. Thus, we hypothesised that the presence of vitreous gel may help restrain the age-related reduction of the macular thickness. Still, the reason for the faster rate of macular thickness reduction in the vitrectomised group compared to the VMS group was not definitively determined.

Lee $e t a l^{21}$ reported that vitrectomy alone does not affect the RNFL thickness. In our study, the individuals in the vitrectomised group were those who had undergone vitrectomy for several non-degenerative retinal diseases and were followed for at least 1 year after the surgery before the first OCT recordings were made. It is unlikely that damages from the vitrectomy affected the mean rate of macular thickness change. Several studies have reported on a significant association between open-angle glaucoma and vitrectomy. ${ }^{22-25}$ The 1-year results of the Prospective Retinal and Optic Nerve Vitrectomy Evaluation Study showed an inferior peripapillary RNFL thinning indicating that an early glaucomatous damage was observed in vitrectomised patients. ${ }^{25}$ In this study, glaucomatous changes were not observed in the vitrectomised group.

The strength of this study is that the patients in the vitrectomised groups were examined at least 1 year after the vitrectomy when the confounding effects of the surgery were somewhat mitigated. There are several limitations to this study. First, the vitrectomised group had concomitant diseases, mostly MHs, that were treated during the surgery and this may have influenced the changes in the macular thickness independent of the vitreous separation. Second, we examined patients who were aged $\geq 56$ years, and the rates of macular thickness reduction may not apply to younger individuals. Third, the results need to be confirmed by a larger sample size because the numbers of eyes in the VMA group as well as in the ILM-on group were small. Fourth, we measured the thickness of the entire retina, and did not measure the thickness of each layer. Some authors have reported that individual retinal layers were selectively affected by age. ${ }^{12}{ }^{13}$ Future studies should be designed to determine whether the reduction in the macular thickness is related to a specific retinal layer.

In conclusion, our results indicated that the age-related reduction of macular thickness was influenced by the presence of a posterior VMA and the presence of vitreous gel. We suggest that the VMA and vitreous gel may help restrain the age-related reduction of the macular thickness. Further studies are necessary to confirm our findings.

Contributors KK and NO contributed to study concept and design, acquisition of data. KK and TS contributed to drafting of the manuscript. KK, $\mathrm{MH}$ and NO were involved in statistical analysis. KK, MF and NO contributed to administrative, technical and material support. $\mathrm{MH}$ and NO were involved in supervision for accuracy and integrity of work. All authors were involved in analysis and interpretation of data and critical revision of the manuscript for important intellectual content and are responsible for final approval of the version to be published.
Funding This research received no specific grant from any funding agency in the public, commercial or not-for-profit sectors.

\section{Competing interests None declared.}

Ethics approval The Ethics Committee of each hospital approved the protocol for this study, and all of the procedures adhered to the tenets of the Declaration of Helsinki.

Provenance and peer review Not commissioned; externally peer reviewed.

Data sharing statement No additional data are available.

Open Access This is an Open Access article distributed in accordance with the Creative Commons Attribution Non Commercial (CC BY-NC 4.0) license, which permits others to distribute, remix, adapt, build upon this work noncommercially, and license their derivative works on different terms, provided the original work is properly cited and the use is non-commercial. See: http:// creativecommons.org/licenses/by-nc/4.0/

\section{REFERENCES}

1. Balazsi AG, Rootman J, Drance SM, et al. The effect of age on the nerve fiber population of the human optic nerve. Am J Ophthalmol 1984;97:760-6.

2. Gao H, Hollyfield JG. Aging of the human retina. Differential loss of neurons and retinal pigment epithelial cells. Invest Ophthalmol Vis Sci 1992;33:1-17

3. Alamouti B, Funk J. Retinal thickness decreases with age: an OCT study. Br J Ophthalmol 2003;87:899-901.

4. Chan A, Duker JS, Ko TH, et al. Normal macular thickness measurements in healthy eyes using Stratus optical coherence tomography. Arch Ophthalmol 2006;124:193-8.

5. Sung KR, Wollstein G, Bilonick RA, et al. Effects of age on optical coherence tomography measurements of healthy retinal nerve fiber layer, macula, and optic nerve head. Ophthalmology 2009;116:1119-24.

6. Eriksson U, Alm A. Macular thickness decreases with age in normal eyes: a study on the macular thickness map protocol in the Stratus OCT. Br J Ophthalmol 2009;93:1448-52.

7. Grover S, Murthy RK, Brar VS, et al. Normative data for macular thickness by high-definition spectral-domain optical coherence tomography (spectralis). Am J Ophthalmol 2009;148:266-71.

8. Song WK, Lee SC, Lee ES, et al. Macular thickness variations with sex, age, and axial length in healthy subjects: a spectral domain-optical coherence tomography study. Invest Ophthalmol Vis Sci 2010;51:3913-18

9. Hirasawa $\mathrm{H}$, Tomidokoro $\mathrm{A}$, Araie $\mathrm{M}$, et al. Peripapillary retinal nerve fiber layer thickness determined by spectral-domain optical coherence tomography in ophthalmologically normal eyes. Arch Ophthalmol 2010;128:1420-6.

10. Kashani AH, Zimmer-Galler IE, Shah SM, et al. Retinal thickness analysis by race, gender, and age using Stratus OCT. Am J Ophthalmol 2010;149:496-502.

11. Duan XR, Liang YB, Friedman DS, et al. Normal macular thickness measurements using optical coherence tomography in healthy eyes of adult Chinese persons: the Handan Eye Study. Ophthalmology 2010;117:1585-94.

12. Ooto S, Hangai M, Sakamoto A, et al. Three-dimensional profile of macular retinal thickness in normal Japanese eyes. Invest Ophthalmol Vis Sci 2010;51:465-73.

13. Ooto S, Hangai M, Tomidokoro A, et al. Effects of age, sex, and axial length on the three-dimensional profile of normal macular layer structures. Invest Ophthalmol Vis Sci 2011;52:8769-79.

14. Leung CK, Yu M, Weinreb RN, et al. Retinal nerve fiber layer imaging with spectral-domain optical coherence tomography: a prospective analysis of age-related loss. Ophthalmology 2012;119:731-7.

15. Leung CK, Cheung CY, Weinreb RN, et al. Comparison of macular thickness measurements between time domain and spectral domain optical coherence tomography. Invest Ophthalmol Vis Sci 2008;49:4893-7.

16. Batta $P$, Engel HM, Shrivastava A, et al. Effect of partial posterior vitreous detachment on retinal nerve fiber layer thickness as measured by optical coherence tomography. Arch Ophthalmol 2010;128:692-7.

17. Stefánsson E, Novack RL, Hatchell DL. Vitrectomy prevents retinal hypoxia in branch retinal vein occlusion. Invest Ophthalmol Vis Sci 1990;31:284-9. 
18. Holekamp NM. The vitreous gel: more than meets the eye. $A m$ $J$ Ophthalmol 2010;149:32-6.

19. Shui YB, Holekamp NM, Kramer BC, et al. The gel state of the vitreous and ascorbate-dependent oxygen consumption: relationship to the etiology of nuclear cataracts. Arch Ophthalmol 2009;127:475-82.

20. Beebe DC, Holekamp NM, Shui YB. Oxidative damage and the prevention of age-related cataracts. Ophthalmic Res 2010;44:155-65.

21. Lee $\mathrm{YH}$, Lee JE, Shin $\mathrm{Yl}$, et al. Longitudinal changes in retinal nerve fiber layer thickness after vitrectomy for rhegmatogenous retinal detachment. Invest Ophthalmol Vis Sci 2012;53:5471-4.
22. Chang S. LXII Edward Jackson lecture: open angle glaucoma after vitrectomy. Am J Ophthalmol 2006;141:1033-43.

23. Luk FO, Kwok AK, Lai TY, et al. Presence of crystalline lens as a protective factor for the late development of open angle glaucoma after vitrectomy. Retina (Philadelphia, Pa) 2009;29:218-24.

24. Siegfried CJ, Shui YB, Holekamp NM, et al. Oxygen distribution in the human eye: relevance to the etiology of open-angle glaucoma after vitrectomy. Invest Ophthalmol Vis Sci 2010;51:5731-8.

25. Lalezary M, Shah RJ, Reddy RK, et al. Prospective Retinal and Optic Nerve Vitrectomy Evaluation (PROVE) study: twelve-month findings. Ophthalmology 2014;121:1983-9. 